\title{
Southwestern Nigerian University Undergraduates' Acceptance of YouTube as a web-based Instructional Tool
}

\author{
Temitope Adetokunbo Oteyola \\ Department of Educational Technology and Library Studies, \\ Obafemi Awolowo University, Ile-Ife, Nigeria \\ Tayo Abbass Bada \\ Department of Educational Technology and Library Studies, \\ Obafemi Awolowo University, Ile-Ife, Nigeria \\ Itunu Olaniran Akande \\ Department of Educational Technology and Library Studies, \\ Obafemi Awolowo University, Ile-Ife, Nigeria
}

\begin{abstract}
The study assessed the Southwestern Nigerian undergraduates' acceptance of YouTube as a web-based instructional tool using Unified Theory of Acceptance and Use of Technology (UTAUT) Model. It determined the level of awareness of YouTube as a webbased instructional tool by the undergraduates. It measured the undergraduates' effort and performance expectancy of YouTube and the conditions that facilitate its acceptance at the universities. The study employed the descriptive survey research design. The population consisted all registered undergraduates in Southwestern Nigeria. 800 students were selected from Obafemi Awolowo University (OAU), Ile-Ife, Osun State, Ladoke Akintola University of Technology (LAUTECH), Oyo State and Covenant University, Ota, Ogun State using disproportionate stratified sampling. The three universities were purposively selected based on their webometric ranking in terms of ICT usage. Findings from the study indicated that $57.80 \%$ of the undergraduates are moderately aware of YouTube as an instructional tool. The effort expectancy $(\bar{x}=3.00, \mathbf{s d}=0.60) \bar{x}=3.11, \mathrm{sd}=0.35)$ as well as the performance expectancy $(\bar{x}=3.00$, sd=0.62) show that the undergraduates accept YouTube. The conditions identified by the undergraduates that can militate the acceptance of YouTube in the region included low bandwidth $(79.70 \%)$, low hard disk space $(65.60 \%)$, epileptic electricity supply $(68.60 \%)$ and high cost of required devices $(68.40 \%)$. The study therefore concluded that Southwestern Nigerian undergraduates are prone to accepting YouTube as a web-based instructional tool.
\end{abstract}

Keywords: YouTube, Students' Perception, Effort Expectancy, Performance Expectancy, Online Learning

\section{INTRODUCTION}

$21^{\text {st }}$ century students are more digitally oriented and driven than those of the pre-information age (McCormick, Holland \& Szydlo, 2010). This is especially so for individuals in their late teens and early twenties who comprise the majority of students that matriculate into university (Greenwood, 2012). The nomenclature for individuals born and bred in the information age is instructive; terms such as Digital natives, Generation X, Web 2.0 generation, Millennials and Net generation are the more popular ones. Duverger and Steffes (2012) argue that these students spend more time watching academic or non-academic content online, especially through YouTube. 
YouTube is a social networking platform with videos as the core contents. Social networking platforms come in many forms from bookmarking services like Delicious, Pinterest, and BibSonomy; to 3D Virtual Worlds like Second life; professional networking systems like LinkedIn; blogging tools like Blogger; microblogging tools like Twitter; collaborative content creation tools such as Wikipedia or Wikispaces; photo sharing services like Flickr and Instagram; profile and friend management/communications systems like Facebook; video sharing services like YouTube; and microvideo blogging services like Vine. Inherent to all these is the concept of user generated content, sharing and social commentary which have been found to encourage students expression and participation as well as foster social learning (Buzzetto-More, 2012). They have all been found particularly effective at appealing to digital natives (BuzzettoMore, 2013). These therefore can serve as an opportunity for using the platforms in engaging students in serious academic activities both formally and informally.

eBizMBA (2018) reported that YouTube is the most dominance of the top 15 most popular video sites visited by an estimated one billion unique visitors per month. eBizMBA ranking which is a continually updated reportage of such information as number of unique monthly visitors, average of each website's traffic rank from Quantcast and global traffic rank from both Alexa and SimilarWeb. It was also reported that about 150 million users visited Netflix; the next rated video viewing website after YouTube.

The possibilities of YouTube videos are of immense advantage for learning. YouTube provides opportunity for learners to learn without the constraints of time and space. The downloaded video from YouTube platform can be played back several times by the learners and thus helps in learning concepts that might have been difficult to understand through repetitiveness. A well designed and articulated instructional video on the platform is likely to arouse students' interest in learning than a conventional face to face method of instruction. Videos on YouTube provide opportunity for classroom activities to be flipped. Students can concentrate on the lower level of the Bloom taxonomy at home while the higher level of analysis, evaluation and creation is done in the classrooms. This could help in preparing the students for challenges in the job world. Appropriate video can be uploaded into YouTube in other to facilitate skills acquisition which will go a long way in improving the employability of the undergraduates after graduation. An effective use of YouTube in facilitating and enhancing teaching and learning can help in confronting the perennial challenges of large class teaching in southwestern Nigeria higher institutions of learning.

As available and accessible as the YouTube platform is, it is something of interest to discover that it has not been efficiently used for instructional purposes in Nigeria. Many reasons could have accounted for this. It is in the light of this that the study investigated on the undergraduates' awareness, effort expectancy, performance expectancy and facilitating conditions that influence the acceptability of this free and educative platform. This becomes necessary so as to solve some of the instructional challenges encountered by Southwestern Nigerian undergraduates.

Performance expectancy as define by Venkatesh, Morris, Davis and Davis (2003) is the degree to which the individuals believe that the use of technology will result in performance gains. This may also be viewed as the perceived usefulness of the technology. Effort expectancy is define as the ease of use of the technology while facilitating conditions is the perceived extent to which the organizational and technical infrastructure required for the support of the technologies exist. It could also be observed that an effective use of YouTube videos for instructional purposes can bring about the opportunity of redirecting the students to engage in profitable and worthwhile exercise while surfing the internet. 
Students oftentimes trust the judgment of their teachers. An academic content uploaded on the YouTube platform by their teachers or link provided by their teachers are very likely to be accessed and viewed by the learners. Learners' interaction with such video is expected to be efficient particularly if they are aware that the video will improve the mastery of the subject matter and if they are aware that it will count towards their grades by the end of the semester. YouTube can therefore be used in engaging students in worthwhile exercise outside the four wall of the classroom. It can also be used in learners' preparation for future challenges.

Amongst other factors, the potential of YouTube and other ICTs in general in facilitating learning and improving performance depends on students' awareness, effort expectancy, performance expectancy and conditions that facilitate their acceptability as instructional tools.

\section{THEORETICAL FRAMEWORK}

This study is premised on the Universal Theory of Acceptance and use of Technology (UTAUT) model as promulgated by Venkatesh, Morris, Davis and Davis (2003). The theory is based on eight technology acceptance theories or models. The UTAUT draws on the Theory of Reasoned Action (TRA), the Technology Acceptance Mode (TAM), the Motivational Model, the Theory of Planned Behaviour (TPB), the combined TAM and TPB, the model of Personal Computer Utilization, the Innovation Diffusion Theory and the Social Cognitive Theory. At the core, the UTAUT model uses behavioural intention as a predictor of the technology use behavior.

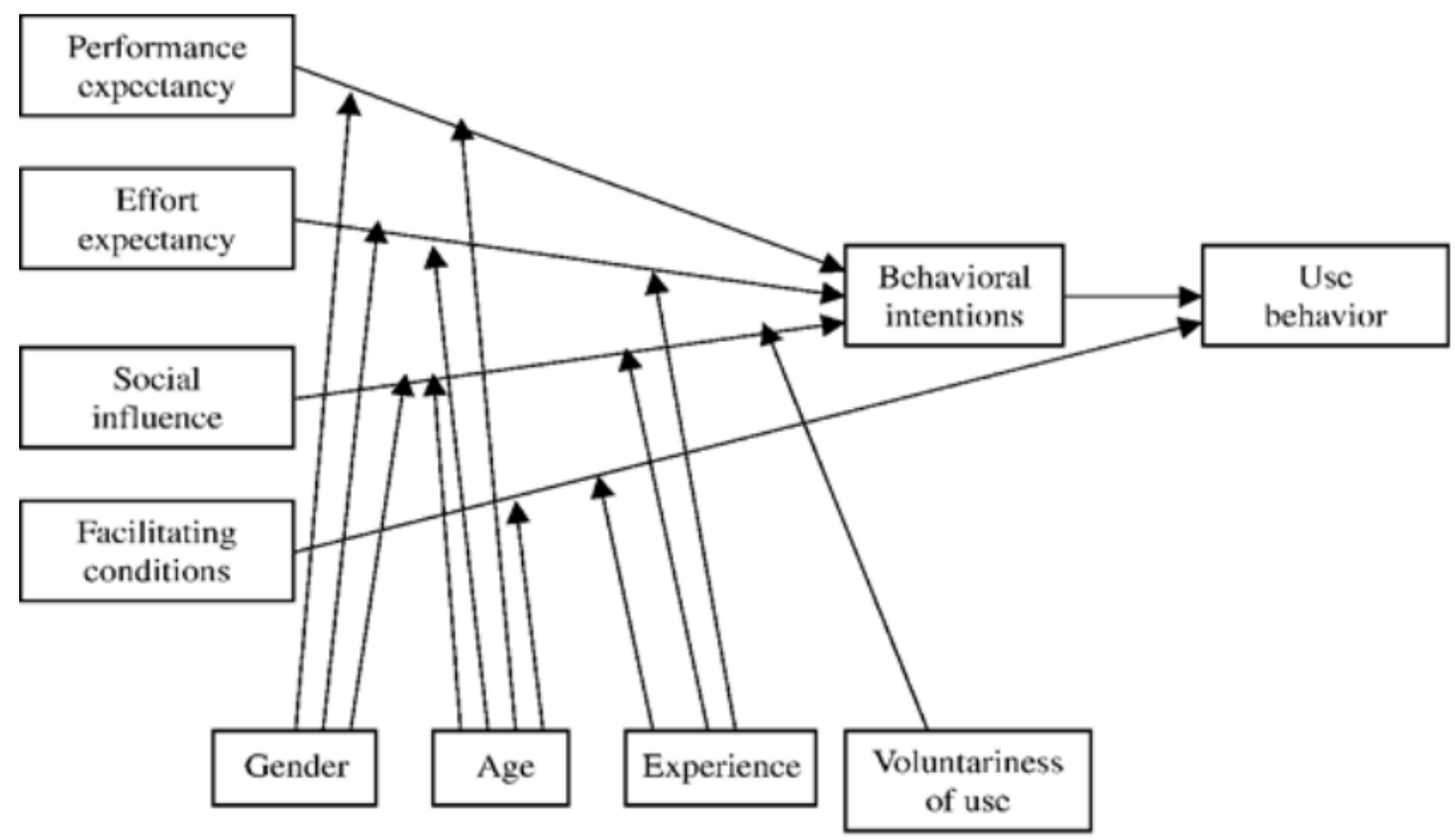

Fig 1: diagrammatic representation of the UTAUT Model (Venkatesh, Morris, Davis and Davis, 2003)

The UTAUT according to Venkatesh et al (2003) consists four constructs which are Performance Expectancy which is defined as the degree to which the individuals believe that the use of technologies will result in performance gains; Effort Expectancy defined as the ease of use of the technology; Social Factors defined as the extent to which the individuals believe that important others believe that they should use the technology and Facilitating Conditions which is defined as the extent to which the organizational and technical infrastructure required for the support of the technologies exist.

The model according to Venhatesh et al (2003) also includes four moderating variables such as age, gender, experience and voluntariness of use. It was posited that in the UTAUT, 
performance expectancy, effort expectancy and social factors have direct effects on behavioural intention. Behavioural intention with facilitating conditions was argued have direct effects on use behavior and hence the acceptability of the technology. The effects of interactions of each of performance expectancy, effort expectancy and social factors with age and gender was also established to affects technology acceptability. The interactions of experience with each of effort expectancy and social factor as well as interaction of voluntariness of use and social factors on behavioural intention was also established.

The UTAUT framework predicted users' acceptance of new technology by approximately $70 \%$ (Moran, Hawkes \& Gayar, 2010). UTAUT's key adfvantage is that it demonstrates superior factor strength. It can explain up to $70 \%$ of variance of intention (Venkatesh et al, 2003). Meister and Compeau (2002) posited that previous technology acceptance model like TAM can only successfully predict the acceptance of an innovation in roughly $30 \%$ to $40 \%$ accuracy. Venkatesh and Davis (2000) also agreed with Meister and Compeau (2002) position. UTAUT also has the advantage of including a distinction between moderating and the determining factors.

\section{Statement of the Problem}

Education today has gone digital; it is therefore imperative to create the need for stakeholders in the sector to appreciate the educational potentials of technologies such as YouTube. Despite the potentials of YouTube in facilitating learning and improving performance, it could be observed that indigenous students have not made the most of the opportunities provided. The reasons for this, amongst others, are arguably traceable to the awareness level, facilitating conditions, performance expectancy as well as effort expectancy by the students. Literatures on the educational use of YouTube in the more developed nations of the world revealed its impact on students' motivation and academic performance. Indigenous university teachers' referral of students to available YouTube instructional videos is perceived to be low despite its educational potentials. Where attempts are made by students, it appears that the students are not culturally familiar with the usage of YouTube as an instructional tool. It is obvious that indigenous students consider YouTube as an entertainment platform. The challenge of access as a result of poor internet connectivity is also opined to affect its acceptability. These and other challenges could likely affect students' acceptability of YouTube as an instructional tool. Thus the opportunities provided by YouTube in students' motivation to engage in round the clock, on the move and self-regulated learning is negatively affected. All these consequently could affect the undergraduates' academic performance. In the light of these, there is need to assess the prevailing level of awareness, effort expectancy, performance expectancy and conditions that facilitate the acceptability of YouTube as an instructional tool by the undergrads. Hence the study.

\section{Objectives of the Study}

The specific objectives of this study are to:

i. assess the Southwestern Nigerian undergraduates' level of awareness of YouTube as a web-based instructional tool;

ii. determine the undergraduates effort expectancy of YouTube as a web-based instructional tool;

iii. determine the undergraduates performance expectancy of YouTube as a web-based instructional tool; and

iv. identify the conditions that can hinder effective use of YouTube as a web-based instructional tool among the undergraduates. 


\section{Research Questions}

i. Are Southwestern university undergraduates aware of YouTube as a web-based instructional tool?

ii. What is the effort expectancy of Southwestern university undergraduates of YouTube as a web-based instructional tool?

iii. What is the performance expectancy of Southwestern university undergraduates of YouTube as a web-based instructional tool?

iv. What are the conditions that can hinder effective use of YouTube as a web-based instructional tool among the Southwestern Nigerian university undergraduates?

\section{METHODOLOGY}

The study employed the descriptive survey research design. The population for the study consisted all registered undergraduates in Southwestern Nigeria. Multistage sampling technique was used in the selection of the sample. All the universities in the region were stratified into Federal, State and Private Universities. This is done so as to give full representation of the various category of universities that can be found in the Southwestern region of Nigeria. Obafemi Awolowo University (OAU), Ile-Ife, Osun State, Ladoke Akintola University of Technology (LAUTECH), Oyo State and Covenant University, Ota, Ogun State were purposively selected for the study. This is based on the ranking of the university in terms of ICT usage as informed by the Webometric rating. Obafemi Awolowo University Ile Ife was the leading ICT University in Nigeria and it was ranked $3^{\text {rd }}$ in the Nigeria webometric ranking. The University was a world Bank designate of centre of excellence in software engineering in Nigeria. The Ladoke Akintola University (LAUTECH), Oyo State was ranked $1^{\text {st }}$ among the state own university in Nigeria while Convenant University (CU) was ranked $1^{\text {st }}$ among and from each of the strata respectively. A sample of 800 students was selected from the three universities using disproportionate stratified random sampling due to the difference in students' population and enrolments across the universities. Five hundred, 200 and 100 undergraduates were selected respectively across the different faculties in the federal, state and private universities. 2UQ which was adapted from Sundaravej (2015) Empirical Validation of Unified Theory of Acceptance and Use of Technology Model and Bing-Tan (2013) Students' Adoptions and Attitudes towards Electronic Placement Tests: A UTAUT Analysis was used for data gathering. 2UQ elicited information on students' awareness, effort expectancy, performance expectancy and conditions that facilitate the acceptability of YouTube as a webbased instructional tool. The instrument was Likert-type, where 1 = strongly disagree, $2=$ disagree, 3 = agree, 4 = strongly agree. The instruments was validated by lecturers in the Department of Educational Technology and Library Studies and also lecturers in the Department of Educational Foundations and Counseling from Obafemi Awolowo University for face, content and construct validity. Item by item analysis was done to eliminate items that were not consistent in measuring what the instrument was expected to measure. To establish the reliability of the instrument, the questionnaire was administered on 20 students at University of Ibadan. The split-half method of reliability testing was employed in determining the reliability of the instrument. Cronbach-Alpha co-efficient of 0.98 was obtained for the instrument. The result showed that the instrument was consistent and reliable.

\section{RESULTS}

Research Question 1: Are Southwestern Nigerian university undergraduates aware of YouTube as a web-based instructional tool? 
Table 1: Descriptive Statistics of Southwestern Nigerian University Undergraduates' Awareness of YouTube as a Web-based Instructional Tool $\mathrm{N}=\mathbf{8 0 0}$

\begin{tabular}{|c|c|c|c|c|c|c|c|}
\hline $\mathbf{S} / \mathbf{N}$ & Item & $\begin{array}{l}\text { SD } \\
(\%)\end{array}$ & D (\%) & $A(\%)$ & SA (\%) & Mean & sd \\
\hline & $\begin{array}{l}\text { Statement: Respondents' Awareness of } \\
\text { YouTube }\end{array}$ & & & & & & \\
\hline 12 & $\begin{array}{l}\text { I have access to devices(s) that allow easy } \\
\text { access to YouTube platform }\end{array}$ & $\begin{array}{c}65 \\
(8.10)\end{array}$ & $\begin{array}{c}52 \\
(6.50)\end{array}$ & $\begin{array}{c}419 \\
(52.40)\end{array}$ & $\begin{array}{c}264 \\
(33.00)\end{array}$ & 3.10 & 0.84 \\
\hline 13 & $\begin{array}{l}\text { I am aware that YouTube can be used for } \\
\text { instructional purposes }\end{array}$ & $\begin{array}{c}27 \\
(3.40)\end{array}$ & $\begin{array}{c}27 \\
(3.40)\end{array}$ & $\begin{array}{c}320 \\
(40.00)\end{array}$ & $\begin{array}{c}426 \\
(53.30)\end{array}$ & 3.43 & 0.72 \\
\hline 14 & $\begin{array}{l}\text { I have at least a YouTube account (gmail, } \\
\text { google+) }\end{array}$ & $\begin{array}{c}59 \\
(7.40)\end{array}$ & $\begin{array}{c}75 \\
(9.40)\end{array}$ & $\begin{array}{c}294 \\
(36.80)\end{array}$ & $\begin{array}{c}372 \\
(46.50)\end{array}$ & 3.22 & 0.90 \\
\hline \multirow[t]{2}{*}{15} & $\begin{array}{l}\text { YouTube is my prime source of online video } \\
\text { viewing/sharing }\end{array}$ & $\begin{array}{c}86 \\
(10.80)\end{array}$ & $\begin{array}{c}159 \\
(19.90)\end{array}$ & $\begin{array}{c}354 \\
(44.30)\end{array}$ & $\begin{array}{c}201 \\
(25.10)\end{array}$ & 2.84 & 0.92 \\
\hline & Respondents' Awareness of YouTube & & & & & 3.15 & 0.64 \\
\hline
\end{tabular}

Table 1.2: Southwestern Nigerian University Undergraduates' Level of Awareness of YouTube as a Web-based Instructional Tool $\mathbf{N}=\mathbf{8 0 0}$

\begin{tabular}{|l|l|l|}
\hline Frequency & Percent & Level of Awareness \\
\hline 217 & 27.10 & High \\
462 & 57.80 & Moderate \\
121 & 15.10 & Low \\
\hline
\end{tabular}

Table 1.1 shows the descriptive statistics of Southwestern Nigerian University undergraduates' awareness of YouTube as a web-based instructional tool. Items 12 to 15 on the questionnaire elicited information on the awareness of YouTube as a web-based instructional tool by the students. Responses from respondents to each item on the questionnaire were scored such that "Strongly Disagree" was scored 1, "Disagree" was scored 2, "Agree" was scored 3 and "Strongly Agree" was scored 4.

The Table shows the frequency, percentage, mean and standard deviation of the responses to each of the items. 246 (33.00\%) strongly agreed to having access to device(s) that allow easy access to YouTube while 419 (52.40\%) agreed to having access to device(s) that allow easy access to YouTube. At least, $683(85.40 \%)$ of the students claimed that they have access to device(s) that allow easy access to YouTube platform while 117 (14.60\%) of the respondents claimed non-access to device(s) that allow easy access to YouTube platform. Table 1.1 also shows the frequency and percentage analysis of the undergraduates' responses to the statement "I am aware that YouTube can be used for instructional purposes". 426 (53.30\%) strongly agreed to the statement while 320 (40.00\%) of the respondents agreed to the statement. $27(3.40 \%)$ of the undergraduates disagreed to the statement while $27(3.40 \%)$ strongly disagreed. At least, 746 (93.30\%) are aware that YouTube can be used for instructional purposes while $54(6.80 \%)$ of the respondents claimed that they are not aware that YouTube can be used for instructional purposes. $372(46.50 \%)$ strongly agreed that they have at least a YouTube account while 294 (36.80\%) agreed that they have at least a YouTube account. At least, $666(83.30 \%)$ of the students claimed that they have at least a YouTube account while $134(16.70 \%)$ of the respondents claimed not to have at least a YouTube account. 201 (25.10\%) strongly agreed that YouTube is their prime source of video viewing/sharing while 354 (44.30\%) agreed that YouTube is their prime source of video viewing/sharing. At least, 555 (69.40\%) of the students claimed that YouTube is their prime 
source of video viewing/sharing while 245 (30.60 \%) of the respondents claimed that YouTube isn't their prime source of video viewing/sharing. The mean of the students' awareness of YouTube was 12.60 and the standard deviation was 2.56. The cumulative mean of the students' awareness was 3.15. This corresponds to "agree" on the scale. Thus it can be suggested that the students agreed that they are aware of YouTube as a web-based instructional tool.

To determine the level of awareness of the students, the responses were categorized into three as shown in Table 1.2 and Figure 1.1. Respondents with aggregate score of 10 and below were categorized as low level of awareness. Those from 15 and above were categorized as high while respondents with aggregate score between 10 and 15 were categorized as moderate. $27.10 \%$ of the respondents had high level of awareness. $57.80 \%$ had moderate and $15.10 \%$ had low level of awareness of YouTube as a web-based instructional tool. It can thus be observed that majority of the students are aware of YouTube as a web-based instructional tool. It can therefore be concluded using majority rule that the students' level of awareness of YouTube as a web-based instructional tool is high. This findings concurred with the defining characteristics of members of the Net Generation as pointed out by Jones, Ramanau, Cross and Healing (2010) who opined that members of the Net Generation are such that have a natural aptitude and high skill levels when using technologies such as YouTube. Such natural aptitude and high skill levels cannot be said to exist outside the context of a significantly high level of awareness of the technology (YouTube). The findings also agree with the result of the study carried out by DeWitt, Zahra and Saedah (2013) in which it was found out that majority of the undergraduates which comprised of $97.2 \%$ used YouTube in their daily life. A similar conclusion was reached by Greenwood (2012) in which the conclusion was reached that the significantly high level of awareness of web 2.0 technologies such as YouTube was especially so for individuals in their late teens and early twenties who comprise the majority of students that matriculate into university.

Research Question 2: What is the effort expectancy of Southwestern university undergraduates of YouTube as a web-based instructional tool?

Table 1.3: Descriptive Statistics of Undergraduates' Effort Expectancy of YouTube as a Webbased Instructional Tool

$\mathbf{N}=\mathbf{8 0 0}$

\begin{tabular}{|c|c|c|c|c|c|c|c|}
\hline $\mathrm{S} / \mathrm{N}$ & Item & SD (\%) & D (\%) & A (\%) & SA(\%) & Mean & sd \\
\hline & Statement: Effort Expectancy & & & & & & \\
\hline 26 & $\begin{array}{l}\text { I enjoy using YouTube videos for } \\
\text { learning }\end{array}$ & $43(5.4)$ & $\begin{array}{c}99 \\
(12.4)\end{array}$ & $\begin{array}{c}473 \\
(59.1)\end{array}$ & $\begin{array}{c}185 \\
(23.1)\end{array}$ & 3.00 & .755 \\
\hline 27 & $\begin{array}{l}\text { YouTube videos are easy to use for } \\
\text { learning. }\end{array}$ & $28(3.5)$ & $\begin{array}{c}98 \\
(12.3)\end{array}$ & $\begin{array}{c}474 \\
(59.3)\end{array}$ & $\begin{array}{c}200 \\
(25.0)\end{array}$ & 3.06 & .714 \\
\hline 28 & $\begin{array}{l}\text { YouTube videos are clear and } \\
\text { understandable. }\end{array}$ & $33(4.1)$ & $\begin{array}{c}80 \\
(10.0)\end{array}$ & $\begin{array}{c}520 \\
(65.0)\end{array}$ & $\begin{array}{c}167 \\
(20.9)\end{array}$ & 3.03 & .714 \\
\hline 29 & $\begin{array}{l}\text { YouTube videos captures and retain } \\
\text { my attention better }\end{array}$ & $23(2.9)$ & $\begin{array}{c}102 \\
(12.8)\end{array}$ & $\begin{array}{c}489 \\
(61.1)\end{array}$ & $\begin{array}{c}186 \\
(23.3)\end{array}$ & 3.05 & .688 \\
\hline 30 & $\begin{array}{l}\text { It is easy for me to become skillful at } \\
\text { using YouTube videos for learning. }\end{array}$ & $37(4.6)$ & $\begin{array}{c}125 \\
(15.6)\end{array}$ & $\begin{array}{c}466 \\
(58.3)\end{array}$ & $\begin{array}{c}172 \\
(21.5)\end{array}$ & 2.97 & .746 \\
\hline 31 & $\begin{array}{l}\text { Using YouTube videos is compatible } \\
\text { with the way I like to learn }\end{array}$ & $46(5.8)$ & $\begin{array}{c}196 \\
(24.5)\end{array}$ & $\begin{array}{c}413 \\
(51.6)\end{array}$ & $\begin{array}{l}145 \\
(18.1)\end{array}$ & 2.82 & .791 \\
\hline & Effort Expectancy & & & & & 3.00 & 0.60 \\
\hline
\end{tabular}

Table 1.3 shows the descriptive statistics of Southwestern University undergraduates' effort expectancy of YouTube as a web-based instructional tool. Items 26 to 31 on the questionnaire elicited information on the effort expectancy by the students. Responses from respondents to each item on the questionnaire were scored such that "Strongly Disagree" was scored 1, 
"Disagree" was scored 2, "Agree" was scored 3 and "Strongly Agree" was scored 4. Table 1.3 shows the frequency, percentage, mean and standard deviation of the responses to each of the items. $185(23.10 \%)$ strongly agreed to the statement: "I enjoy using YouTube videos for learning" while 473 (59.10\%) agreed to the statement. At least, 658 (82.20\%) of the students claimed that they enjoy using YouTube videos for learning while $142(17.80 \%)$ of the respondents claimed they do not enjoy using YouTube videos for learning. Table 1.3 also shows the frequency and percentage analysis of the undergraduates' responses to the statement "YouTube videos are easy to use for learning". 200 (25.00\%) strongly agreed to the statement while $474(59.30 \%)$ of the respondents agreed to the statement. $98(12.30 \%)$ of the undergraduates disagreed to the statement while 28 (3.50\%) strongly disagreed. At least, 674 $(84.30 \%)$ claimed that YouTube videos are easy to use for learning while $126(15.80 \%)$ of the respondents claimed that they are not aware that YouTube can be used for instructional purposes. 167 (20.90\%) strongly agreed that YouTube videos are clear and understandable while 520 (65.00\%) agreed that YouTube videos are clear and understandable. At least, 687 $(85.90 \%)$ of the students claimed that YouTube videos are clear and understandable while 113 $(14.10 \%)$ of the respondents claimed that YouTube videos are not clear and understandable. $186(23.30 \%)$ strongly agreed to the statement: "YouTube videos captures and retain my attention better" while $489(61.10 \%)$ agreed to the statement. At least, $675(84.40 \%)$ of the students claimed that YouTube videos captures and retain their attention better while 125 $(15.60 \%)$ of the respondents claimed that YouTube videos do not capture and retain their attention better. $172(21.50 \%)$ strongly agreed to the statement: "It is easy for me to become skillful at using YouTube videos for learning." while 466 (58.30\%) agreed to the statement. At least, $638(79.80 \%)$ of the students claimed that it is easy for them to become skillful at using YouTube videos for study/learning while $162(20.20 \%)$ of the respondents claimed that it is not easy for them to become skillful at using YouTube videos for learning. 145 (18.10\%) strongly agreed to the statement: "Using YouTube videos is compatible with the way I like to learn" while 413 (51.60\%) agreed to the statement. At least, 558 (69.70\%) of the students claimed that using YouTube videos is compatible with the way they like to learn while 242 $(30.30 \%)$ of the respondents claimed that using YouTube videos is not compatible with the way they like to learn. The mean of the students' effort expectancy of YouTube was 3.00 and the standard deviation was 0.60. This corresponds to "agree" on the scale. Thus it can be observed that the students agreed that there is a significantly high degree of ease associated with the use of YouTube as a web-based instructional tool.

Research Question 3: What is the performance expectancy of Southwestern university undergraduates of YouTube as a web-based instructional tool? 
Table 1.4: Descriptive Statistics of Undergraduates' Performance Expectancy of YouTube as a Web-based Instructional Tool

$\mathbf{N}=\mathbf{8 0 0}$

\begin{tabular}{|c|c|c|c|c|c|c|c|}
\hline $\mathbf{S} / \mathbf{N}$ & Item & SD (\%) & D (\%) & A (\%) & SA (\%) & Mean & sd \\
\hline & Statement: Performance Expectancy & & & & & & \\
\hline 20 & $\begin{array}{l}\text { I believe that YouTube Videos could make me } \\
\text { learn faster }\end{array}$ & $41(5.1)$ & $\begin{array}{c}88 \\
(11.0)\end{array}$ & $\begin{array}{c}437 \\
(54.6)\end{array}$ & $\begin{array}{c}234 \\
(29.3)\end{array}$ & 3.08 & .776 \\
\hline 21 & $\begin{array}{l}\text { I believe that YouTube Videos could make me } \\
\text { learn better }\end{array}$ & $34(4.3)$ & $\begin{array}{c}65 \\
(8.1)\end{array}$ & $\begin{array}{c}458 \\
(57.3)\end{array}$ & $\begin{array}{c}243 \\
(30.4)\end{array}$ & 3.14 & .733 \\
\hline 22 & $\begin{array}{l}\text { I believe that YouTube Videos could improve } \\
\text { my academic results }\end{array}$ & $52(6.5)$ & $\begin{array}{c}116 \\
(14.5)\end{array}$ & $\begin{array}{c}419 \\
(52.4)\end{array}$ & $\begin{array}{l}213 \\
(26.6)\end{array}$ & 2.99 & 820 \\
\hline 23 & $\begin{array}{l}\text { Using YouTube increases my motivation to } \\
\text { learn. }\end{array}$ & $41(5.1)$ & $\begin{array}{c}132 \\
(16.5)\end{array}$ & $\begin{array}{c}421 \\
(52.6)\end{array}$ & $\begin{array}{c}206 \\
(25.80)\end{array}$ & 2.99 & .793 \\
\hline 24 & $\begin{array}{l}\text { Using YouTube motivates me to ask questions } \\
\text { about my academic challenges from my } \\
\text { instructor without been shy or afraid. }\end{array}$ & $70(8.8)$ & $\begin{array}{c}240 \\
(30.0)\end{array}$ & $\begin{array}{c}372 \\
(46.5)\end{array}$ & $\begin{array}{c}118 \\
(14.8)\end{array}$ & 2.67 & 831 \\
\hline 25 & $\begin{array}{l}\text { I think YouTube can deliver curriculum } \\
\text { content in a meaningful and effective way? }\end{array}$ & $40(5.0)$ & $\begin{array}{c}88 \\
(11.0)\end{array}$ & $\begin{array}{c}500 \\
(62.5)\end{array}$ & $\begin{array}{c}172 \\
(21.5)\end{array}$ & 3.01 & .725 \\
\hline & Performance Expectancy & & & & & 3.00 & 0.62 \\
\hline
\end{tabular}

Table 1.4 shows the descriptive statistics of Southwestern University undergraduates' performance expectancy of YouTube as a web-based instructional tool. Items 20 to 25 on the questionnaire elicited information on the performance expectancy of YouTube as a web-based instructional tool by the students. Responses from respondents to each item on the questionnaire were scored such that "Strongly Disagree" was scored 1, "Disagree" was scored 2, "Agree" was scored 3 and "Strongly Agree" was scored 4.

The Table also shows the frequency, percentage, mean and standard deviation of the responses to each of the items. $234(29.30 \%)$ strongly agreed to the statement: "I believe that YouTube Videos could make me learn faster" while 437 (54.6\%) agreed to the statement. At least, 671 $(83.90 \%)$ of the students claimed that they believe YouTube Videos could make them learn faster while 129 (16.10\%) of the respondents claimed they do not believe YouTube Videos could make them learn faster. Table 1.4 also shows the frequency and percentage analysis of the undergraduates' responses to the statement "I believe that YouTube Videos could make me learn better". 243 (30.40\%) strongly agreed to the statement while $458(57.30 \%)$ of the respondents agreed to the statement. $65(8.10 \%)$ of the undergraduates disagreed to the statement while 34 (4.30\%) strongly disagreed. At least, 701 (87.70\%) claimed that they believe YouTube Videos could make them learn better while $99(12.40 \%)$ of the respondents claimed they do not believe YouTube Videos could make them learn better. 213 (26.60\%) strongly agreed that YouTube Videos could improve their academic results while 419 $(52.40 \%)$ agreed that YouTube Videos could improve their academic results. At least, 632 (79.00\%) of the students claimed that YouTube Videos could improve their academic results while 168 (21.00\%) of the respondents claimed that YouTube Videos could not improve their academic results. 206 (25.80\%) strongly agreed to the statement: "using YouTube increases my motivation to learn" while 421 (52.60\%) agreed to the statement. At least, 627 (78.40\%) of the students claimed that using YouTube increases their motivation to learn while 173 (21.60 $\%)$ of the respondents claimed that using YouTube does not increase their motivation to learn. $118(14.80 \%)$ strongly agreed to the statement: "Using YouTube motivates me to ask questions about my academic challenges from my instructor without been shy or afraid." while 372 $(46.50 \%)$ agreed to the statement. At least, 490 (61.30\%) of the students claimed that using YouTube motivates them to ask questions about my academic challenges from the instructor without been shy or afraid while $310(38.70 \%)$ of the respondents claimed that using YouTube 
does not motivate them to ask questions about my academic challenges from the instructor without been shy or afraid. $172(21.50 \%)$ strongly agreed to the statement: "I think YouTube can deliver curriculum content in a meaningful and effective way" while $500(62.50 \%)$ agreed to the statement. At least, $672(84.00 \%)$ of the students claimed they think YouTube can deliver curriculum content in a meaningful and effective way while $128(16.00 \%)$ of the respondents claimed they do not think YouTube can deliver curriculum content in a meaningful and effective way. The mean of the students' performance expectancy of YouTube was 3.00 and the standard deviation was 0.62 . This corresponds to "agree" on the scale. Thus it can be observed that the students agreed that there is a significantly believes that using YouTube as a web-based instructional tool has positive impact on their performance. The results on effort and performance expectancy are consistent with the findings of Alimemaj (2010) in which students implied their acceptability of YouTube based on their perception of YouTube as a great potential resource for learning and relatively free of effort in terms of usage. Using the framework of the UTAUT, perception is considered as an aggregated variable consisting of performance expectancy, effort expectancy, facilitating condition and other variables. By implication, factors of performance expectancy, effort expectancy and facilitating conditions have direct bearing in shaping the respondents' acceptability of YouTube. It is perceived that using a technology tool such as YouTube will improve learning performance outcomes. It was also revealed that YouTube can be used with relative ease. This understanding is in alignment with the findings of Balcikanli (2011) where the results from a study about YouTube in learning lead to the conclusion that students reckoned YouTube as being of advantage because of the associated benefits of improving learning performance, competence and independent skill.

Research Question 4: What are the conditions that can hinder effective use of YouTube as a web-based instructional tool among Southwestern Nigerian universities undergraduates?

Table 1.5: Descriptive Statistics of Conditions that can hinder effective use of YouTube as a Web-based Instructional Tool

$\mathbf{N}=\mathbf{8 0 0}$

\begin{tabular}{|c|l|c|c|c|c|}
\hline S/N & Item & SD (\%) & D(\%) & A(\%) & SA(\%) \\
\hline & Statement: Possible Usage Challenges (PUC) & & & & \\
\hline \multirow{2}{*}{51} & Low bandwidth hinders my usage of YouTube for & $44(5.5)$ & 119 & 386 & 251 \\
& study/learning & & $(14.9)$ & $(48.3)$ & $(31.4)$ \\
& Low hard disk space hinders my usage of YouTube for & $69(8.6)$ & 206 & 360 & 165 \\
52 & study/learning & & $(25.8)$ & $(45.0)$ & $(20.6)$ \\
& Irregular electricity/power supply hinders my usage of & 86 & 165 & 337 & 212 \\
53 & YouTube for study/learning & $(10.8)$ & $(20.6)$ & $(42.1)$ & $(26.5)$ \\
54 & The high cost of the required devices hinders my usage of & $74(9.3)$ & 179 & 337 & 210 \\
& YouTube for study/learning & $(22.4)$ & $(42.1)$ & $(26.3)$ \\
55 & Low technical know-how hinders my usage of YouTube for & 207 & 258 & 227 & 108 \\
& study/learning & $(25.9)$ & $(32.3)$ & $(28.4)$ & $(13.5)$ \\
\hline
\end{tabular}

Each of the identified factors was subjected to a frequency count and percentage in order to understand the responses of the respondents. Table 1.5 shows the descriptive statistics of students' usage challenges of YouTube as a web-based instructional tool. Item 51 represented the question; Low bandwidth hinders my usage of YouTube for study/learning. Item 52 represented the question; Low hard disk space hinders my usage of YouTube for study/learning. Item 53 represented the question; Irregular electricity/power supply hinders my usage of YouTube for study/learning. Item 54 represented the question; the high cost of the required devices hinders my usage of YouTube for study/learning and item 55 represented the question; Low technical know-how hinders my usage of YouTube for study/learning. 
Responses from respondents to each item on the questionnaire were scored such that "Strongly Disagree" was scored 1, "Disagree" was scored 2, "Agree" was scored 3 and "Strongly Agree" was scored 4. Table 1.5 shows the frequency, percentage analysis, mean and standard deviation of the responses to each of the items. $251(31.40 \%)$ strongly agreed that low bandwidth hinders their usage of YouTube for study/learning while 386 (48.30\%) agreed that low bandwidth hinders their usage of YouTube for study/learning. At least, 637 (79.70\%) of the students claimed that low bandwidth hinders their usage of YouTube for study/learning while $163(20.30 \%)$ of the students claimed low bandwidth does not hinder their usage of YouTube for study/learning.

$165(20.60 \%)$ strongly agreed that low hard disk space hinders their usage of YouTube for study/learning while $360(45.00 \%)$ agreed that low hard disk space hinders their usage of YouTube for study/learning. At least, 525 (65.60\%) of the students claimed that low hard disk space hinders their usage of YouTube for study/learning while 275 (34.40\%) of the students claimed low hard disk space does not hinder their usage of YouTube for study/learning.

$212(26.50 \%)$ strongly agreed that irregular electricity/power supply hinders their usage of YouTube for study/learning while 337 (42.10\%) agreed that irregular electricity/power supply hinders their usage of YouTube for study/learning. At least, 549 (68.60\%) of the students claimed that irregular electricity/power supply hinders their usage of YouTube for study/learning while 251 (31.40\%) of the students claimed irregular electricity/power supply does not hinder their usage of YouTube for study/learning.

$210(26.30 \%)$ strongly agreed that the high cost of the required devices hinders their usage of YouTube for study/learning while 337 (42.10\%) agreed that the high cost of the required devices hinders their usage of YouTube for study/learning. At least, 547 (68.40\%) of the students claimed that the high cost of the required devices hinders their usage of YouTube for study/learning while 253 (31.60\%) of the students claimed the high cost of the required devices does not hinder their usage of YouTube for study/learning.

$108(13.50 \%)$ strongly agreed that low technical know-how hinders their usage of YouTube for study/learning while 227 (28.40\%) agreed that low technical know-how hinders their usage of YouTube for study/learning. At least, 335 (41.90\%) of the students claimed that low technical know-how hinders their usage of YouTube for study/learning while 465 (58.10\%) of the students claimed low technical know-how does not hinder their usage of YouTube for study/learning.

Using the simple majority rule, the conditions identified by the undergraduates that affect the acceptability of YouTube as a web-based instructional tool in Southwestern Nigerian Universities are:
i. Low bandwidth
ii. Low hard disk space
iii. Irregular electricity/power supply
iv. High cost of required devices

This finding tally with that of Morrison, Oyedele, Oladunjoye and Maman (2017) in their study on the utilization of social media in Nigeria in which it was discovered that part of the significant challenges affecting the adoption of YouTube for instructional purposes were similar to those identified in the result of this study. The findings of Singh and Hardaker (2014) also concurred with that of this study. 


\section{CONCLUSION}

From the findings of this study, it was concluded that the acceptability of YouTube as a webbased instructional tool by Southwestern Nigeria undergraduates is high. Lack of relevant literatures on undergraduates' acceptability of YouTube is militating its adoption by higher institutions of learning in Nigeria. Probably one of the reasons indigenous lecturers had not engaged in uploading educational and instructional videos on the platform.

\section{RECOMMENDATIONS}

On the basis of the findings of this study, the following recommendations were made:

i. Indigenous educators are encouraged to use YouTube and other web 2.0 tools in order to take advantage of their inherent possibilities and also to improve on the teachinglearning context for contemporary students within and outside of the conventional classrooms particularly in large classes.

ii. YouTube has the potential to be an outlet for students and educators to create change, exchange information and collaborate. To reach this potential, educators need to shift from treating this video viewing and sharing website as simply 'virtual libraries' to a space of socializing, commenting, creating, collaborating and assessing. With this shift comes a responsibility to utilizing YouTube for educational purposes in an effective, collaborative and informative way.

iii. Available instructional videos on YouTube are majorly from foreign instructors. More local contents should be uploaded by educators, content developers and other stakeholders in order to improve Indigenous students' usage of the platform. This should be done with considerations on theoretical frameworks guiding the effective and efficient development and presentation of multimedia information.

iv. Educational institutions should offer needed training, support services and required infrastructures to educators in order to make the development of instructional videos and the usage of YouTube for instructional purposes relatively easy. Educators should also be open to collaborations with students as most of the students, being digital natives could serve as trainers, supports group, content providers/developers to the educators when it comes to the usage of web 2.0 tools such as YouTube.

v. Educational institutions should consider investments in providing optimal and stable internet quality for students in order to improve students' accessibility to YouTube.

vi. Continuous orientation of students by all stakeholders should be carried out in order to minimize the possible distractions and potential abuse of the YouTube platform.

\section{References}

Alexa Top 500 Global Sites. (2018). Viewed June 10, 2018 http://www.alexa.com/topsites.

Alimemaj, Z. (2010). YouTube: Language Learning and Teaching Techniques. The Magazine of Global English Speaking Higher Education, 2 (3) 10-12.

Balcikanli, C. (2011). Long Live, YouTube. L2 Stories about YouTube in Language Learning. viewed July 20, 2018 http://moodle.bracu.ac.bd/mod/resource/view.php?id=8

Bing-Tan, P.J. (2013). Students Adoption and Attitudes towards Electronic Placement Tests: A UTAUT Analysis. American Journal of Computer Technology and Application 1 (1) 14 - 23

Buzzetto-More, N. (2012). Social Networking in Undergraduate Education. Interdisciplinary Journal of Information, Knowledge and Management, 7 (1) 63-90.

Buzzetto-More, N. (November, 2013). The Use of Youtube to Engage Digital Natives: Student Preferences and Perceptions in Online and Hybrid Courses. Paper presented at the 19th Annual SLOAN Consortium International Conference on Online Learning. Orlando, Florida: SLOAN Consortium. 20-22 November viewed January 3, 2019 http://secure.onlinelearningconsortium.org/conference/2013

DeWitt, D., Zahra N. \& Saedah S. (2013). Technology Applications Used by First Year Undergraduates in a Malaysian Public University. Social and Behavioral Sciences, 103, 937 - 945. 
Duverger, P. \& Steffes, E. M. (2012). Edutainment With Videos and Its Positive Effect On Long Term Memory. Journal for Advancement of Marketing Education, 20 (1) 1-10

Greenwood, G. (2012). Examining the Presence of Social Media on University Websites. Journal of College Admission, 216 (1) 24-28.

Jones, C., Ramanau, R., Cross, S. \& Healing, G. (2010). Net generation or Digital Natives: Is there a Distinct New Generation Entering University? Computers and Education, 54 (3) 722-732.

McCormick, J. G., Holland, S. \& Szydlo, L. R. 2010. Experiential Learning 2.0: Incorporating YouTube in Leisure Studies. A Journal of Leisure Studies and Recreation Education, 25, 74-78.

Morrison, J.L., Oyedele, J., Oladunjoye, G.T. \& Maman, J. (2017). The Utilization of Social Media in the Classroom by Business Teacher Educators in Nigeria. Africa Journal of Teacher Education, 6 (1) 22-38.

Singh, G. \& Hardaker, G. (20140. Barriers and Enablers to Adoption and Diffusion of E-learning: A Systematic Review of the Literature-A Need for an Integrative Approach. Education + Training, 56 (2) 105-121

Sundaravej, T. (2015). Empirical Validation of Unified Theory of Acceptance and use of Technology Model. Journal of Global Information Technology Management 13, 5 - 27

Venkatesh, V., Morris, M. G., Davis, G. B. \& Davis, F. D. 2003. User Acceptance of Information Technology: Toward a Unified View. MIS Quarterly, 27 (3) 425-478. 